\title{
Neuroimmune alterations of ENS functioning
}

\author{
L Bueno
}

\section{Introduction}

Only recently has it been considered that numerous interactions between the enteric nervous system and local immunocytes are responsible for adaptive functional changes, including motility and secretion (fig 1). Several neuropeptides such as tachykinins, vasoactive intestinal peptide, somatostatin, and opioids are involved in both intrinsic and extrinsic innervation but can also affect immune reactions directly. They exert a dual role in the regulation of local and peripheral motor and secretory reflexes and affect the release of cytokines and proinflammatory mediators. On the other hand, proinflammatory mediators such as eicosanoids and cytokines may activate intrinsic neurones directly or stimulate extrinsic neurones indirectly, releasing neuropeptides which act on intrinsic neurones, smooth muscle cells, or enterocytes. These acute immediate neuroimmune reactions are often followed by long term changes in the number of receptors at the presynaptic or postsynaptic level as well as phenotypic changes of the effector cells, as evidenced for smooth muscle cells and enteric neurones which can synthetise cytokines.

\section{Major gut targets in inflammation}

There are at least three major target cells affected by the presence of inflammatory mediators: smooth muscle cells, glial cells, and neurones. Both intrinsic enteric neurones and terminals of extrinsic afferent and efferent nerves are affected (fig 2). Indeed, phenotypic changes in smooth muscle cells under the influence of proinflammatory mediators consist mainly of expression and release of cytokines. $^{1} \mathrm{Up}$ and downregulation of a number of receptors for neuromediators ${ }^{2}$ and neuropeptides ${ }^{3}$ have also been demonstrated. Indeed, the number of alpha and beta adrenoceptors is inversely altered in the acute phase of inflammation in the guinea pig ileum. Mast cells, leukotrienes, and prostaglandins are involved in this up and downregulation of receptors, and changes in the physical properties of smooth muscle have also been demonstrated both in vitro and in vivo.

Inflammation induces neuronal phenotypic changes and affects the release of mediators in the gut intrinsic nervous system (fig 3). The myenteric plexus may secrete cytokines such as interleukin (IL) 1 and tumour necrosis factor $\alpha$ $(\mathrm{TNF}-\alpha)^{4}$, but also interferon $\gamma^{5}$ and transforming growth factor $\beta,{ }^{6}$ although the physiological role of such secretions remains unknown. The presence of cytokines in the proximity of the myenteric plexus during inflammation may affect the release of classical neurotransmitters and the number of receptors for them and for neuropeptides, as well as altering electrophysiological properties. For example, it has been shown that IL-1 $\beta$, through release of leukaemia inhibitory factor, de-

Abbreviations used in this paper: $\mathrm{ACh}$, acetylcholine; IL, interleukin; TNF- $\alpha$, tumour necrosis factor $\alpha$; NAd, noradrenaline; 5-HT, 5-hydroxytryptamine.
Department of Pharmacology INRA, Neurogastroenterology Unit, 180 Chemin de Tournefeuille BP3, 31931 Toulouse, France L Bueno

Correspondence to: Dr L Bueno.

lbueno@toulouse.inra.fr

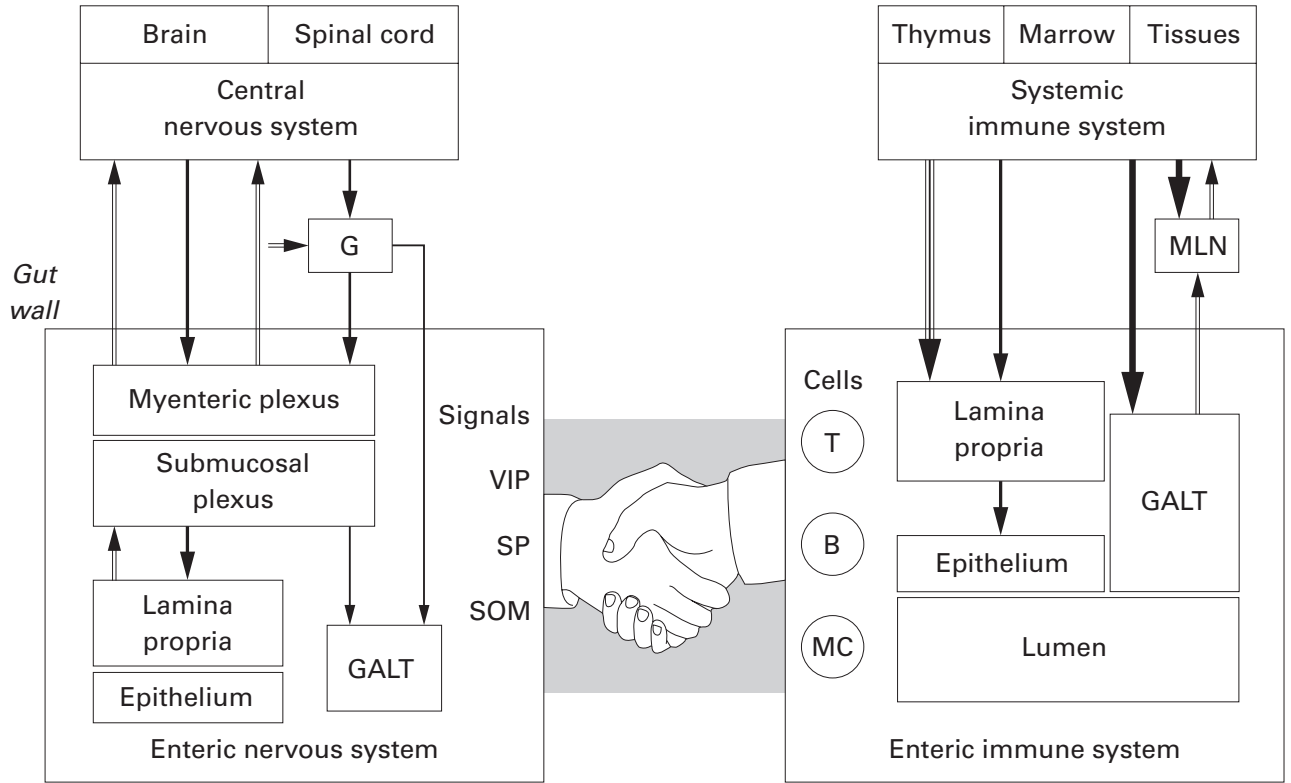

Figure 1 Interaction between the central nervous system and the immune system. VIP, vasoactive intestinal peptide; SP, substance P; SOM, somatostatin; G, ganglion; GALT, gut associated lymphoid tissue; MLN, mesenteric lymph node. (From Ottaway. ${ }^{20}$ ) 
Figure 2 Influence of inflammatory mediators on extrinsic afferent and efferent nerves. LT, leukotriene; $P G s$, prostaglandins; NGF, nerve growth factor; CGRP, calcitonin gene related peptide; 5-HT,

5-hydroxytryptamine; diHETE,

dihydroxyeicosatetraenoic acid.
Figure 3 Inflammation induced phenotypic changes and mediator release in the gut intrinsic nervous system. IL, interleukin; TNF- $a$, tumour necrosis factor $\alpha$; TGF- $\beta$, transforming growth factor $\beta$; LIF, leukaemia inhibitory factor; ACh, acetylcholine; $i N O S$, inducible nitric acid synthase; NAd, noradrenaline.

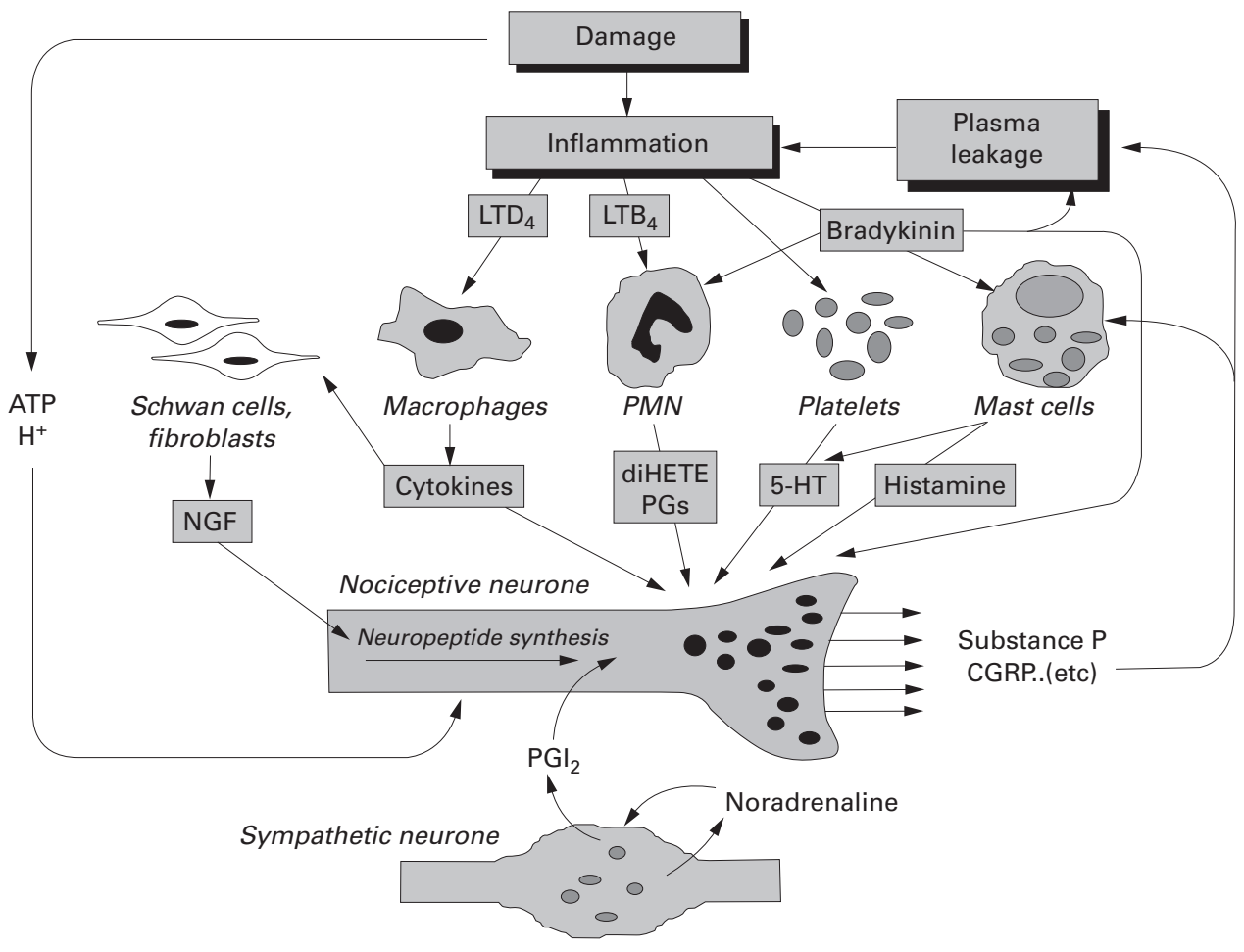

creases the release of acetylcholine $(\mathrm{ACh})^{7}$ and increases the activity or expression of inducible nitric acid synthase. ${ }^{8}$ TNF- $\alpha$ may also selectively affect noradrenergic function by reducing the release of noradrenaline (NAd) ${ }^{9}$ from myenteric plexus, while IL-6 may decrease or increase this NAd release, depending of its concentration. ${ }^{10}$ Release of other mediators may also be influenced by inflammatory mediators as altered responsiveness to histamine and 5-hydroxytryptamine (5-HT), as well as to carbachol, was observed in inflamed guinea pig ileal strips. ${ }^{11}$ Electrophysiological measurements have recently permitted the characterisation of changes in resting potential or in spontaneous firing, as well as in the dura-

tion and amplitude of fast excitatory postsynaptic potentials in the guinea pig jejunal myenteric plexus during $T$ spiralis infection. ${ }^{12}$ From a functional point of view, the time course of inflammation development in trinitrobenezene sulphonic acid induced colitis in rats is associated with typical alterations in electrical spike activity, corresponding to a progressive increase in the duration of electrical spike bursts. These alterations are transiently suppressed by systemic administration of IL-1 receptor antagonist, suggesting that the activity of myenteric neurones controlling colonic motility during inflammation are permanently modulated by cytokines. ${ }^{13}$ In addition, some neuroimmune connections may ini-

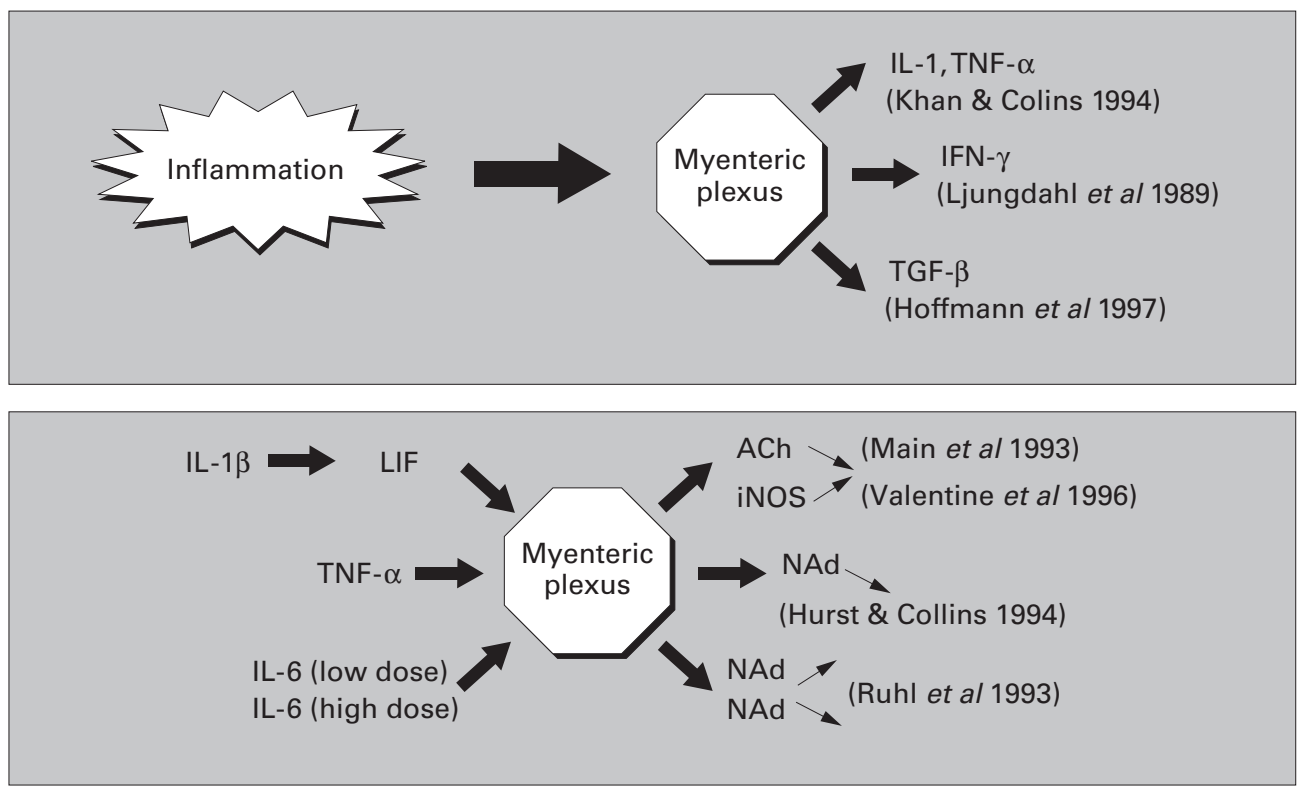


Table 1 Pathological motility disorders and the enteric nervous system

\begin{tabular}{|c|c|c|c|c|}
\hline Type & $\begin{array}{l}\text { Inflammatory } \\
\text { mediators }\end{array}$ & Cytokines & Neurotransmitters & Neuropeptides \\
\hline Inflammation (acute) & $\mathrm{LTB}_{4}$ & IL-1 & $\begin{array}{l}5-\mathrm{HT}\left(5-\mathrm{HT}_{1 \mathrm{~A}} / 5-\mathrm{HT}_{3}\right) \\
\mathrm{NO}\end{array}$ & $\begin{array}{l}\mathrm{BK}\left(\mathrm{B}_{2}\right) \\
\mathrm{SP}\left(\mathrm{NK}_{1}\right)\end{array}$ \\
\hline Anaphylaxis & $\mathrm{PGE}_{2}$ & IL-1 & $\begin{array}{l}\text { 5- HT }\left(5-\mathrm{HT}_{3}\right) \\
\text { Histamine }\left(\mathrm{H}_{1}\right)\end{array}$ & $\mathrm{SP}\left(\mathrm{NK}_{1}\right)$ \\
\hline Parasitism & & & $\begin{array}{l}5-\mathrm{HT}\left(5-\mathrm{HT}_{3}\right) \\
\mathrm{ACh}\left(\mathrm{M}_{1}\right)\end{array}$ & $\begin{array}{l}\mathrm{SP}\left(\mathrm{NK}_{1}\right) \\
\mathrm{NKA}\left(\mathrm{NK}_{2}\right)\end{array}$ \\
\hline Septic shock & $\begin{array}{l}\mathrm{PGE}_{2}\left(\mathrm{EP}_{2}\right) \\
\mathrm{PAF}\end{array}$ & $\begin{array}{l}\text { IL-1 } \\
\text { TNF- } \alpha\end{array}$ & $\begin{array}{l}\text { NAd }\left(\alpha_{1} / \alpha_{2}\right) \\
\text { NO }\end{array}$ & $\mathrm{CRF}$ \\
\hline
\end{tabular}

$\mathrm{LTB}_{4}$, leukotriene $\mathrm{B}_{4} ; \mathrm{IL}$, interleukin; $\mathrm{PGE}_{2}$, prostaglandin $\mathrm{E}_{2}$; PAF, platelet activating factor; TNF- $\alpha$, tumour necrosis factor $\alpha$; 5 -HT, 5-hydroxytryptamine; NO, nitric oxide; NAd, noradrenaline; BK, bradykinin; ACh, acetylcholine; SP, substance P; NK, neurokinin; CRF, corticotrophin releasing factor. particularly afferent vagal fibres. During challenge, degranulation of mast cells is associated with local release of IL-1 which in turn activates vagal afferent fibres directly or indirectly through release of $5-\mathrm{HT}$ and activation of the $5-\mathrm{HT}_{3}$ receptor subtype. ${ }^{17}{ }^{18}$ Similarly, alterations of the intestinal motor pattern associated with septic shock also involve both intrinsic and extrinsic innervation, with an important role for vagal afferents and local activation of the nitrergic component ${ }^{19}$ (table 1 ).

Finally, our present knowledge supports the concept that activation of the gut immune system triggers immediate and persistent alterations of the enteric nervous system, which could be responsible for chronic dysfunctioning such as that observed in functional bowel disorders such as irritable bowel syndrome. new distribution of neuronal endings affecting both intrinsic and extrinsic neurones and consequently ascending and descending pathways participating in peristaltic reflexes.

\section{Role of ENS in altered gut secretory and motor patterns}

There is increasing evidence that substance $P$, mast cells, and nitric oxide are strongly involved in local activation of intrinsic neurones in motor and secretory effects of enterotoxins such as cholera toxin, Clostridium difficile, and Escherichia coli toxins. For example, cholera toxin activates receptors located on Escherichia coli cells, releasing IL-1 and activating mast cell degranulation, which in turn releases substance P. This sensory neuropeptide is activated indirectly via vasoactive intestinal peptidergic neurones in close proximity to enterocytes. Local immune reactions are also involved in gastrointestinal motor disturbances induced by sepsis and anaphylactic reactions. In this context, cytokines such as IL-1 and $\mathrm{TNF}-\alpha$, as well as platelet activating factor, participate locally in the genesis of these motor alterations through modulation of the enteric nervous system.

In vitro, it has also been shown that inflammation affects the responsiveness of both the myenteric and submucosal plexus to chemical or physical stimuli. In the peristaltic reflex elicited by field stimulation, both ascending and descending contractile reflex pathways are inhibited by exogenous IL-1. This effect seems not to be mediated by prostaglandins or via histamine receptors. Moreover, in the inflamed ileum, phosphatidylinositol hydrolysis may be essential to stimulate phasic contractions, and inflammation may downregulate the protein kinase C pathway. ${ }^{14}$

Recent results have established that intrinsic and extrinsic enteric neurones are involved in the regulation of inflammatory processes and may indirectly affect local neuroimmune reactions. In several models of experimental inflammation, intrinsic denervation as well as destruction of sensory $\mathrm{C}$ fibres affect the local immune reactions, with a cytoprotective role of these neuronal components. ${ }^{15}{ }^{16}$ Alterations in motility related to anaphylactic challenge in sensitised rats involve extrinsic innervation and
1 Collins SM. The immunomodulation of enteric neuromuscdisorders. Gastroenterology 1996;111:1683-99.

2 Martinolle JP, Garcia-Villar R, More J, et al. Evidence for mast cell, leukotriene and nitric oxide involvement in the regulation of the adrenoceptor number of inflamed small intestine in guinea pigs. Neurogastroenterol Motil 1995; 187-95.

3 Jeanneton O, Delvaux M, Langlois Y, et al. Correlation of desensitisation of platelet activating factor (PAF) receptors with intensity of inflammation and intestinal PAF content 356-64.

4 Khan I, Collins SM. Expression of cytokines in the longitudinal muscle myenteric plexus of the inflamed intestine of

5 Ljungdahl A, Olsson T, Van der Meide PH, et al. Interferongamma-like immunoreactivity in certain neurons of the central and peripheral nervous system. 7 Neurosci Res 1989 ; 24:451-6.

6 Hoffmann P, Zech JM, Lakshmanan J, et al. Transforming growth factor alpha-immunoreactivity in neural tissues of growth factor alpha-immunoreactivity in ne
the rat stomach. Regul Pept 1997;69:121-5.

7 Main C, Blennerhassett P, Collins SM. Human recombinant interleukin I beta suppresses acetylcholine release from rat myenteric plexus. Gastroenterology 1993;104: 1648-54

8 Valentine IF, Tannahill CL, Stevenot SA, et al. Colitis and interleukin 1beta up-regulate inducible nitric oxide synGastroenterology 1996;111:56-64.

9 Hurst SM, Collins SM. Mechanism underlying tumor necrosis factor-alpha suppression of norepinephrine release from rat myenteric plexus. Am f Physiol 1994;266:G1123-9.

10 Ruhl A, Hurst SM, Collins SM. Synergism between interleukins 1 beta and 6 on noradrenergic nerves in rat interleukins 1 beta and 6 on noradrenergic nerves in rat
myenteric plexus. Gastroenterology 1994,107:993-1001.

11 Martinolle JP, Garcia-Villar R, Fioramonti J, et al. Altered contractility of circular and longitudinal muscle in TNBSinflamed guinea pig ileum. Am 7 Physiol 1997;272: G1258-67.

12 Palmer JM, Wong-Riley M, Sharkey KA. Functional alterations in jejunal myenteric neurons during inflammation in G922-35. and interleukin 1 are involved in colonic dysmotility in 14 Sama SK. In vivo signal-transduction pathways to stimulate phasic contractions in normal and inflamed ileum. Am $\mathcal{F}$ phasic contractions in normal

15 Reinshagen M, Patel A, Sottili M, et al. Protective function of extrinsic sensory neurons in acute rabbit experimental colitis. Gastroenterology 1994;106:1208-14.

16 Mazelin L, Theodorou V, More J, et al. Protective role of vagal afferents in experimentally-induced colitis in rats. $\mathcal{F}$ Auton Nerv Syst 1998;73:38-45.

17 Theodorou V, Fioramonti J, Junien IL, et al. Anaphylactic colonic hypersecretion in cow's milk sensitized guinea-pigs depends upon release of interleukin-1, prostaglandins and mast cell degranulation. Aliment Pharmacol Ther 1994;8: 301-7.

18 Castex N, Fioramonti J, Fargeas MJ, et al. Role of 5-HT3 receptors and afferent fibers in the effects of mast cell degranulation on colonic motility in rats. Gastroenterology 1994;107:976-84.

19 Fargeas MJ, Fioramonti J, Bueno L. Central action of interleukin 1 beta on intestinal motility in rats: mediation by two leukin 1 beta on intestinal motility in rats: mediation
mechanisms. Gastroenterology 1993;104:377-83.

20 Ottaway CA. Neuroimmunomodulation in the intestinal mucosa. Gastroenterol Clin North Am 1991;20:511-29. ular function: implications for motility and inflammatory during experimental ileitis in guinea pig. Gut 1998;43: rat. Gastroenterology 1994;107:691-700. thase and superoxide dismutase in rat myenteric neurons. nematode-infected guinea pigs. Am $\mathcal{F}$ Physiol 1998;275:

13 Morteau O, More J, Pons L, et al. Platelet-activating factor 